\title{
Evaluation of Formation Water Chemistry and Scale Prediction: Bakken Shale.
}

Geoffrey Thyne ${ }^{1}$ and Patrick Brady ${ }^{2}$

\begin{abstract}
Determination of in situ formation water chemistry is an essential component of reservoir management. This paper details the use of thermodynamic computer models to calculate reservoir $\mathrm{pH}$ and restore produced water analyses for prediction of scale formation. Bakken produced water samples were restored to formation conditions and calculations of scale formation performed. In situ $\mathrm{pH}$ is controlled by feldspar-clay equilibria. Calcite scale is readily formed due to changes in $\mathrm{pH}$ during pressure drop from in situ to surface conditions. The formation of anhydrite and halite scale, which has been observed, was predicted only for the most saline samples. In addition, the formation of anhydrite and/or halite may be related to the localized conditions of increased salinity as water is partitioned into the gas phase during production.
\end{abstract}

\section{Introduction}

1.1 Accurate formation water chemistry is essential for the design of drilling and completion fluids, ensuring fluid compatibility, avoiding corrosion damage, souring, fines mobilization, clay swelling and scale precipitation, as well as design of surface fluid handling facilities (Abdou et al, 2011, Bader, 2007, Baraka-Lokmane and Sorbie, 2010, El-Said et al. 2009, Holubnyak et al. 2011, Kan et al. 2014, Kodel et al. 2010, Mosghadasi et al. 2004, Shosh and Li, 2013). In particular, the precipitation of calcium carbonate and sulfates, barium sulfate and iron scales in wellbores and surface facilities are an on-going problem for most petroleum fields worldwide (Mahmoud, 2014, Zahedzadeh et al. 2014). These scales are deposited in the wellbore during production significantly reducing the flow capacity. Scale volumes can be calculated if the initial formation water chemistry is known. However, water samples taken at the wellhead often differ compared to formation water because of reactions that occur in transit, providing an uncertain basis for scale prediction. Specifically, the components of scale are lost from the produced water and must be correctly restored to accurately simulate scale formation.

Standard geochemical modeling codes can restore parameters such as calcium, alkalinity and $\mathrm{pH}$ to reservoir values by assuming equilibrium with formation minerals before production (Miller et 
al. 1976, Fu et al. 2013, Haghtalab et al. 2014, Holubnyak et al. 2011). There are specialized software packages available to calculate potential scaling (Haghtalab et al. 2014, Zahedzadeh et al. 2014, , Gomes et al. 2012, Fan et al. 2010), although some authors have chosen to employ standard geochemical codes (Fu et al. 2013, Zhang et al. 2010). Regardless of the details of the calculations, all the models rely on good quality input data. In particular, the reservoir $\mathrm{pH}$ and alkalinity is critical when dealing with carbonate scale (Kan and Tomson, 2012, Zhang et al. 2010). The objectives of this paper are to perform an evaluation of Bakken reservoir fluids, and then use standard geochemical models to restore produced water analyses to in-situ conditions. Our approach focuses on restoration of reservoir $\mathrm{pH}$, a critical parameter in carbonate scale prediction (Haghtalab et al. 2014, Kan and Tomson, 2012). Our method assumes that reservoir $\mathrm{pH}$ is controlled by mineral equilibrium, but unlike prior work we specifically examine the likelihood of feldspar-clay reactions controlling reservoir $\mathrm{pH}$.

\section{$47 \quad 1.2 \quad$ Bakken Formation}

The Bakken Shale is a prolific hydrocarbon producer in the Williston Basin. The Bakken is an intracratonic basin with a relatively simple structure that encompasses portions of South Dakota, North Dakota, Montana, Saskatchewan and Manitoba. The basin formation water is typically very saline due to dissolution of salts including anhydrite and halite (Bachu and Hitchon, 1996, Iampen and Rostron, 2000). The Bakken Formation ranges from 0 to 140 feet, thickening toward basin center (Tran et al. 2011). The productive middle member of the Bakken Formation is composed of silt-sized clay, carbonate and silicate minerals together with up to 5-10\% organic matter. The Bakken Formation is considered to be an aquitard (Hitchon, 1996) and so is hydrologically isolated from the general west to east topographically-driven basinal flow in the aquifer units (Bachu and Hitchon, 1996). The low permeability of the shale has trapped generated oil within the formation, further reducing permeability to water flow. No Bakken oil has escaped to the overlying Madison group (Ramakrishna et al. 2010).

In the Bakken, production of oil is preceded by formation of fracture networks to facilitate flow. The hydraulic fracturing process forces large volumes of fluid into the formation (LaFollette et al. 2012). This fluid is mostly low salinity water together with proppants and chemicals injected into the low permeability rock under pressure. Pressure is then released and hydrocarbons flow to the well. The return of injected fluids is termed flowback. During flowback the chemistry of the produced water gradually changes from fracturing and completion fluids to mixtures with formation water. In the Bakken, between 15 to $40 \%$ of the injected fluid does not return to the surface but instead remains in the formation (Boschee, 2014). The fluid entrained in the formation continues to mix and react with formation water, reservoir minerals and organic matter. Most wells deplete rapidly and reach stable low production rates within a year.

Petrographic studies have shown the middle Bakken member is composed of silt-sized dolomite and mono-crystalline quartz with minor amounts of potassium feldspar, plagioclase, volcanic rock fragments, muscovite, calcareous grains and skeletal fragments. The authigenic phases are 
mostly carbonate cements, dolomite and calcite. Dolomite grains may have ferroan rims. Other authigenic features include quartz and K-feldspar overgrowths, and anhydrite and pyrite. Clays are predominantly illite ( $<5 \%$ expandable) and minor chlorite and kaolinite (Ashu, 2014, Kurtoglu et al. 2014, Pitman et al. 2001, Ramakrishna et al. 2010). There are no reports of halite in the middle Bakken, however, the underlying salt beds in the Middle Devonian Prairie Evaporite Formation do contain halite (Iampen and Rostron, 2000).

\section{Methods}

Chemical analyses of Bakken Formation water were compiled from the USGS Produced Waters database and several literature sources (Griffin et al. 2014, Gupta et al. 2012, Kurtoglu et al, 2014, Zhou et al. 2014a, Zhou et al. 2014b). The samples were from depths of 10,000 to 12,000 feet. The initial dataset had 423 samples from the USGS database and 12 samples from the other literature sources. The USGS produced water database is a compilation of numerous databases, reports and publications updated over time (USGS 2016). The produced water samples are submitted and have varying level of detail regarding sampling issues and potential QA/QC problems. The samples sometimes lack such information such as measured depth, sample dates and specific parameters.

Therefore we used the pre-screening process now described. Samples with missing data for the major solutes were discarded with the exception of five samples lacking alkalinity. An average value was substituted in those cases assuming carbonate equilibrium. Because the alkalinity represents less than $1 \%$ of the anionic portion of the solutes, this estimation has no discernable impact on the charge balance or total dissolved solids values. Next, the charge balance was calculated and samples with charge imbalance greater than $\pm 10 \%$ were removed from further evaluation. In a few cases examination of the analyses showed obvious errors in data entry that could be corrected to restore charge balance. Total dissolved solids (TDS) were measured on less than $10 \%$ of the samples so the TDS was calculated as the sum of the major solutes. The $\mathrm{r}^{2}$ of the linear regression of calculated TDS versus measured TDS was 0.966. Reported sample depths ranged from 9,834 to 11,134 feet, averaging 10,227 feet. In situ temperature was calculated for samples that reported depth using the geothermal gradient and reported depth. The average temperature was $123^{\circ} \mathrm{C}$ with temperatures ranging from 106 to $133^{\circ} \mathrm{C}$. For samples that did not report depth or temperature we use $120^{\circ} \mathrm{C}$ during calculations.

The final dataset consisted of 369 samples with calculated TDS ranging from $963 \mathrm{mg} / \mathrm{l}$ to $343,833 \mathrm{mg} / \mathrm{l}$. This dataset is large enough for statistical analysis, identification of outliers and recognition of composition trends. This size database ensures the modeling results are robust and avoids conclusions based on non-typical water samples. Scaling calculation and geochemical modeling were performed using the commercial program Geochemist's Workbench $^{\mathrm{TM}}$ (Bethke, 1996) and PHREEQC (Parkhurst et al. 1999), a public-domain software. The standard databases include the Pitzer and standard activity models. 
Reservoir $\mathrm{pH}$ values are usually calculated using gas analyses and the assumption of carbonate equilibrium (Lundegard and Land, 1989, Kan et al. 2013, Fu et al. 2012). An alternative hypothesis that we explore below is that in situ $\mathrm{pH}$ is controlled by silicate mineral buffering (feldspar and clay) (e.g. Baccar and Fritz, 1993, Helgeson et al. 1993, Hutcheon et al., 1993, Smith and Ehrenberg, 1989). These slower silicate reactions set reservoir $\mathrm{pH}$ and more rapid carbonate reactions respond accordingly. The in situ $\mathrm{pH}$ is estimated by assuming $\mathrm{K}$ feldspar/Kaolinite equilibrium at reservoir temperatures, using $\log \mathrm{K} \approx-3.8$ (Smith and Ehrenberg, 1989) and the dissolved potassium values for each water sample (Equation 1).

$$
\mathrm{H}^{+}+\mathrm{KAlSi}_{3} \mathrm{O}_{8}+1 / 2 \mathrm{H}_{2} \mathrm{O} \leftrightarrow 1 / 2 \mathrm{Al}_{2} \mathrm{Si}_{2} \mathrm{O}_{5}(\mathrm{OH})_{4}+\mathrm{K}^{+}+2 \mathrm{SiO}_{2, \mathrm{qtz}}
$$

$$
\mathrm{a}_{\mathrm{K}+} / 10^{3.8}=\mathrm{a}_{\mathrm{H}+}
$$

First, we calculate the $\mathrm{a}_{\mathrm{K}}+$ using the reported $\mathrm{pH}$ and potassium value for each analysis with the PHREEQC-1lnl database. This database is common to both computer codes and contains the carbonate, chloride and sulfate minerals of interest. The same activity model (Davies) was used throughout the calculations once the initial evaluation of activity models was completed (see section 3.2). The calculated $\mathrm{a}_{\mathrm{K}}+$ value is then used to calculate the in situ $\mathrm{pH}$ value using Equation 1. The procedure is iterated to converge on a final value. We found no change in calculated $\mathrm{pH}$ after the second iteration.

\section{RESULTS}

\subsection{Bakken Formation Water}

Formation water samples from the Bakken are generally very saline with total dissolved solids as high as 350,000 mg/l. Solutes are dominantly sodium and chloride with some potassium, calcium and magnesium, bicarbonate and sulfate with minor amounts of iron, barium, boron, and strontium. The higher salinity data is consistent with reported water chemistry in Williston basin formation waters (Iampen and Rostron, 2000). Figure 1 shows a Piper plot for the Bakken formation water analyses. The plot shows that solutes are mainly $\mathrm{Na}$ and $\mathrm{Cl}$ with minor amounts of $\mathrm{Ca}$ in some lower TDS samples.

Figure 2 shows TDS versus chloride content for the water samples together with an imbedded figure showing the distribution of values. The histogram indicates that while most samples have higher TDS, there are samples with low TDS that form a distinct population. The linear regression line for the data has an $\mathrm{r}^{2}$ of 0.99 and a y-intercept of 2,570 ppm TDS. The injected water in the Bakken has total salinity of approximately 5,000 ppm (e.g. Kurtoglu, 2014).

Water from adjacent formations may contribute to flowback and production if the hydraulic fractures extend out of the relatively thin Bakken formation. Evaluation of 544 samples from the overlying Madison and Mission Creek and underlying Winnipegosis Formations were made using the same methodology and from the locations as the Bakken samples. The evaluation 
145 shows water compositions from the underlying formations that are similar to the Bakken, 146 indicating the lower salinity Bakken samples are not a result of contributions from the adjacent 147 formations. Samples with low TDS probably represent early flowback. The majority of the 148 early flowback is composed of hydraulic fracturing fluid with little or no formation brine. As 149 noted above the hydraulic fracturing fluid is relatively fresh with an average TDS of $5000 \mathrm{ppm}$. 150 Therefore, we only used 310 samples with TDS greater than 180,000 TDS for further evaluation.

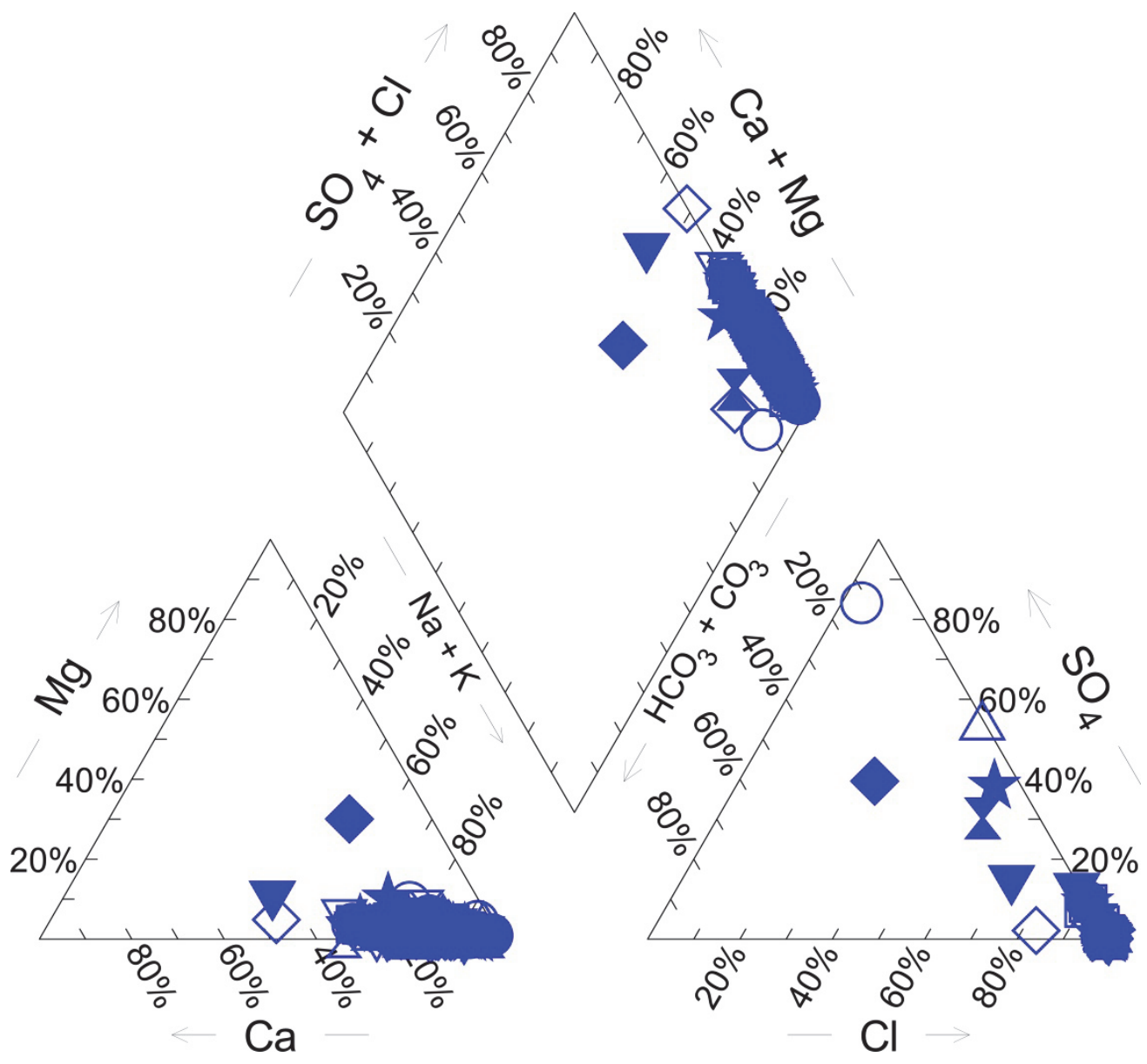

153 Figure 1. Piper plot of all Bakken samples. 


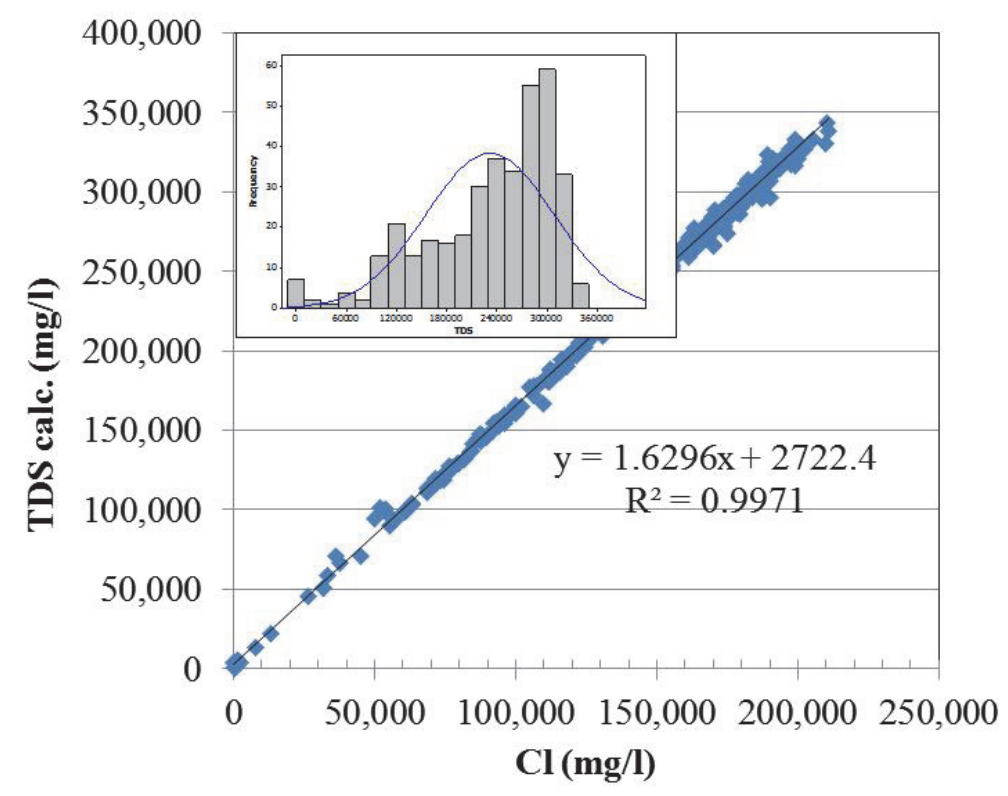

154

155 Figure 2. Total dissolved solids (calculated) versus chloride. Inset histogram shows the 156 distribution of TDS in the Bakken produced water database.

\section{$157 \quad 3.2 \quad$ Activity Model Evaluation}

158 The highly saline formation water in the Bakken has an ionic strength greater than 4. In default mode PHREEQC (Parkhurst and Appelo, 1999) uses the Davies activity model while GWB uses the B-dot formulation (Bethke, 1996), but both modeling tools also include their own versions of a Pitzer database. In high ionic strength solutions, the use of traditional activity coefficient models such as the Davies equation or the extended Deybe-Huckel (B-dot) has been questioned. Instead, the Pitzer activity coefficient model is often used given multicomponent electrolytes and extensive parameterization in salt systems (Bethke, 1996).

165 To evaluate which activity model is the most effective for the Bakken we used PHREEQC to calculate the saturation for anhydrite, a mineral present in the formation, with the PHREEQC, $1 \mathrm{lnl}$ and Pitzer databases. The PHREEQC and llnl databases use the default activity model, while 168 the Pitzer database uses the ion-pair activity formulation. The calculated saturation for quartz and anhydrite should be relatively insensitive to $\mathrm{pH}$, allowing the calculations to be made with wellhead $\mathrm{pH}$ values. During production some calcite is precipitated and the temperature is lowered. Both of these processes should cause under-saturation of the produced water with

172 respect to anhydrite since calcium is removed from solution and anhydrite solubility is 173 retrograde, that is increases as temperature is lowered.

174 Figure 3 shows the results of the saturation index (SI) versus TDS for anhydrite. The Pitzer 175 activity formulation produces saturation indices for anhydrite that are unlikely - persistent over- 
saturation - given that, if saturated, anhydrite should precipitate rapidly. The PHREEQC database gives more plausible results, but still shows many samples that are over-saturated. An obvious goal of further analysis is determination of the source of the discrepancy in the Pitzer prediction of anhydrite saturation. In the meantime, because the $1 \mathrm{ln} l$ database produces the results most consistent with the observed mineralogy, it will be used for $\mathrm{pH}$ and brine chemistry restoration.

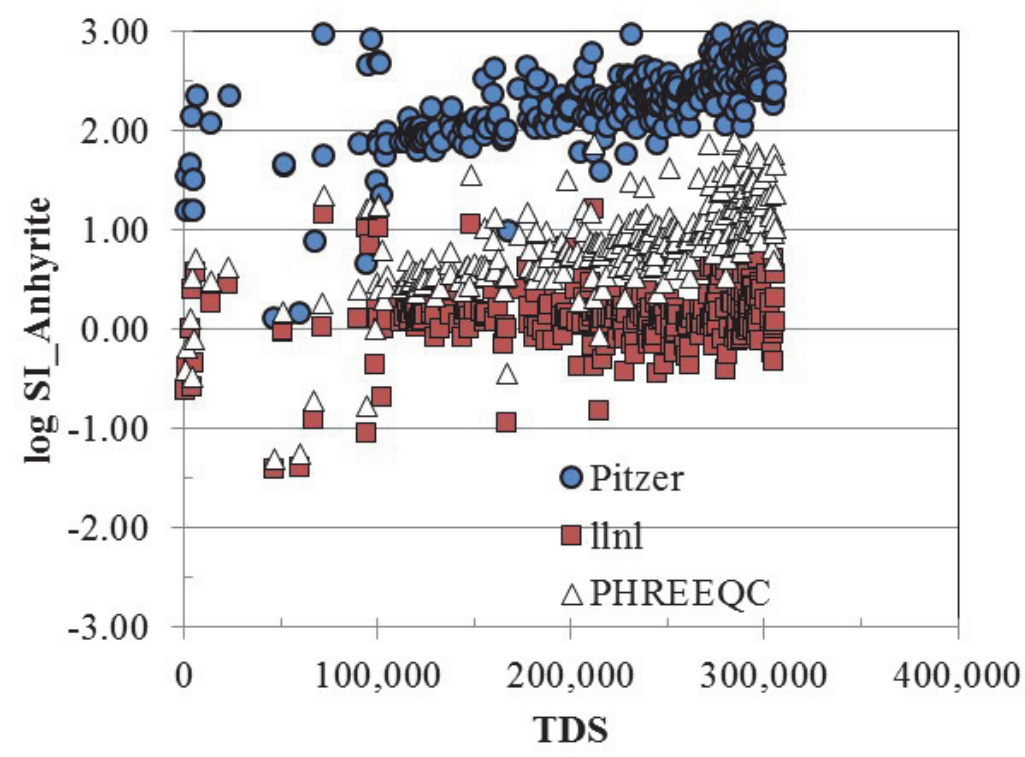

Figure 3. Calculated calcite saturation indices for anhydrite versus TDS for Bakken samples. Calculation were made using three different databases.

187 In petroleum reservoirs, water-rock reaction rates are anticipated to quickly reach chemical equilibrium with silicate and carbonate minerals within weeks to months after introduction of non-equilibrium fluids (Houston et al. 2007). Petrographic examination of the Bakken shows the presence of quartz and K-spar including late stage overgrowths, dolomite and calcite, pyrite and occasional anhydrite, but no halite. In addition, the clay minerals illite, kaolinite, and chlorite were reported. We anticipate that the formation water should be in equilibrium with quartz, 193 carbonate minerals and anhydrite given the rate of rock-water reactions at high temperature (106$\left.194133^{\circ} \mathrm{C}\right)$.

195 The assumption of equilibrium with quartz can be tested. Figure 4 shows quartz saturation 196 indices plotted against total dissolved solids for Bakken samples with dissolved silica analyses. 
197 The data show that the produced water samples are at, or near, equilibrium with respect to

198 quartz; given the uncertainties in temperature and the possible effects of scale formation during 199 rise to the surface, it is likely that formation waters are in equilibrium with quartz. This 200 calculation is in agreement with the observations of late-stage quartz overgrowths (Pitman et al. 201 2001).

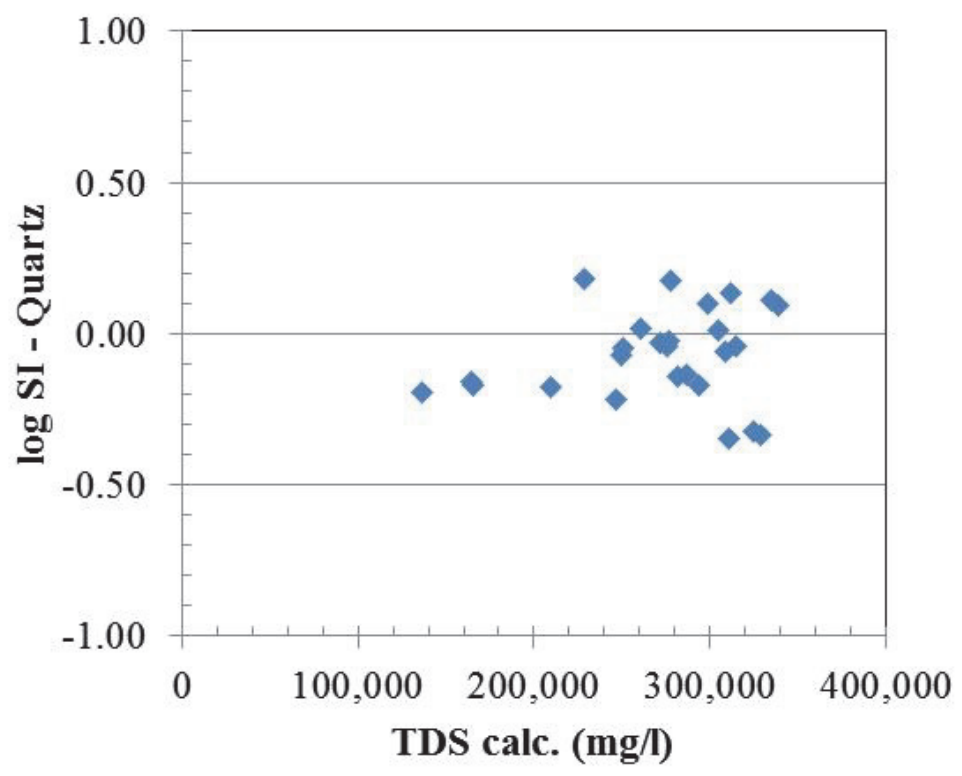

203 Figure 4. Calculated $\log \mathrm{SI}$ (saturation index) for quartz at $120^{\circ} \mathrm{C}$ versus total dissolved solids 204 (calculated). Saturation with respect to quartz is equal to 0 in units of $\log$ SI. Calculated using 205 GWB (b-dot) and llnl database.

206 Figure 5 shows the 310 calculated saturation indices for halite and anhydrite. As mentioned 207 above the saturation for chloride and sulfate salts is fairly insensitive to $\mathrm{pH}$. The calculated 208 values are reasonable since, while there is no halite in the Bakken, the Williston basin brines are 209 known to be derived from halite dissolution. The high degree of under-saturation for halite in 210 the lower TDS samples is consistent with dilution of normal brines by drilling and completion 211 fluids. The presence of anhydrite in the formation is consistent with the calculated saturation, or 212 near saturation, for the produced water samples. 


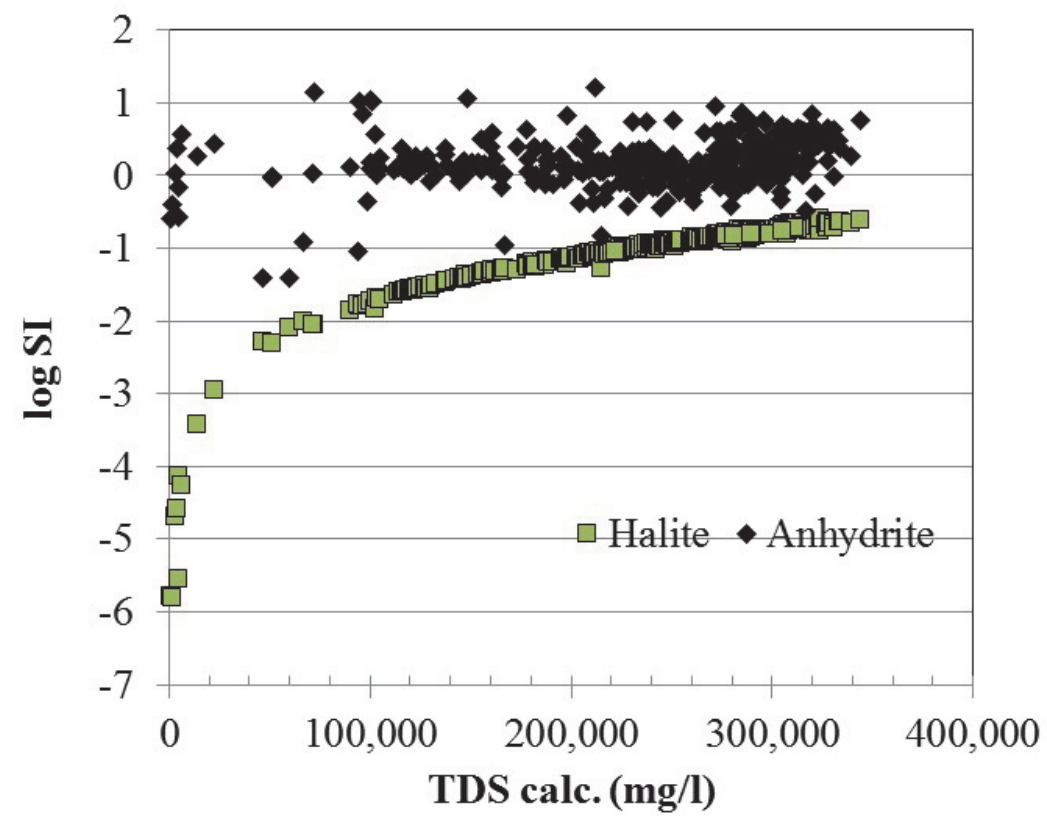

214 Figure 5. Saturation indices for Anhydrite and Halite versus TDS for Bakken produced water 215 samples. Saturation is equal to zero for log saturation index (SI).

\section{$216 \quad 3.3 \quad$ Reservoir $\mathrm{pH}$ Calculations}

217 Figure 6 shows the calculated in situ pH values for 310 samples, with mean values of 5.08 using 218 the GWB and 5.1 using the PHREEQC. The difference in calculated $\mathrm{pH}$ for each model is a 219 result of slightly different calculated values of $\mathrm{a}_{\mathrm{K}+}$. The in situ $\mathrm{pH}$ values are an average of $1 \mathrm{pH}$ 220 unit lower than the wellhead $\mathrm{pH}$ values. Since calculated $\mathrm{pH}$ depends on reported potassium 221 concentration we evaluated the reported values to assess their accuracy. Potassium is a minor 222 component and therefore has little impact on the charge balance. Instead we calculated the $\mathrm{Na} / \mathrm{K}$ 223 ration for all samples. The ratio was usually around $15-20$ with less than $10 \%$ of the samples 224 having ratios as high as 100. Four samples were eliminated because they had much higher 225 ratios $<$ presumably due to low reported potassium values. Samples with lower potassium will 226 produce calculated $\mathrm{pH}$ values that are slightly more alkaline $(<0.5 \mathrm{pH}$ units). 


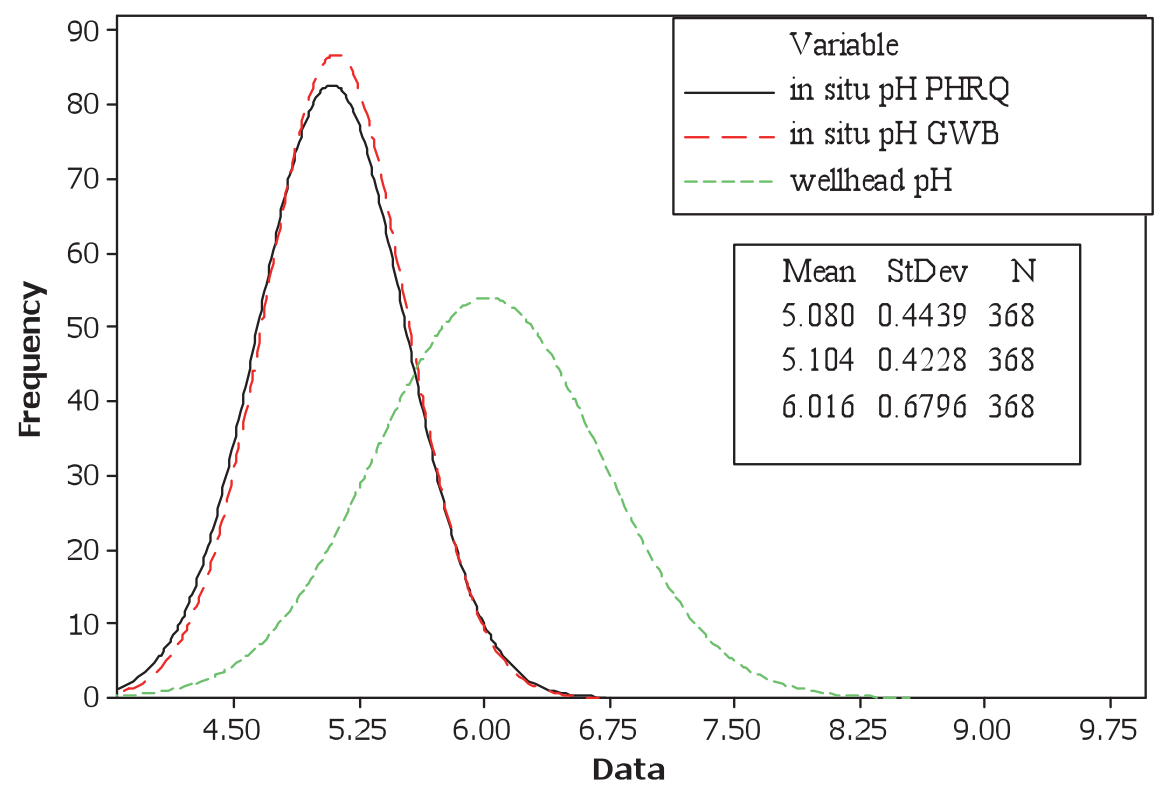

232

233 Figure 6. Wellhead and in situ $\mathrm{pH}$ values (calculated for K-Feldspar-kaolinite equilibrium and 234 potassium activities derived with GWB and PHREEQC using the default activity model and lnl 235 database) at $120^{\circ} \mathrm{C}$.

236 We evaluate the calculated reservoir $\mathrm{pH}$ values by plotting the original and restored water 237 analyses on the mineral stability diagram for this system (Güler and Thyne, 2004). Figure 7 238 shows the mineral stability diagram for the $\mathrm{K}_{2} \mathrm{O}-\mathrm{NaO}-\mathrm{SiO}_{2}-\mathrm{MgO}-\mathrm{Al}_{2} \mathrm{O}_{3}-\mathrm{H}_{2} \mathrm{O}$ system with the 239 produced water analyses using the reported $\mathrm{pH}$ values and after the in situ $\mathrm{pH}$ was calculated. 240 The reported values plot well above the phase boundary for the reservoir silicate minerals. In 241 contrast, when the reservoir $\mathrm{pH}$ values are used, all the data is clustered near the phase 242 boundaries for kaolinite-K-feldspar, illite-K-feldspar or K-feldspar-illite-kaolinite. 


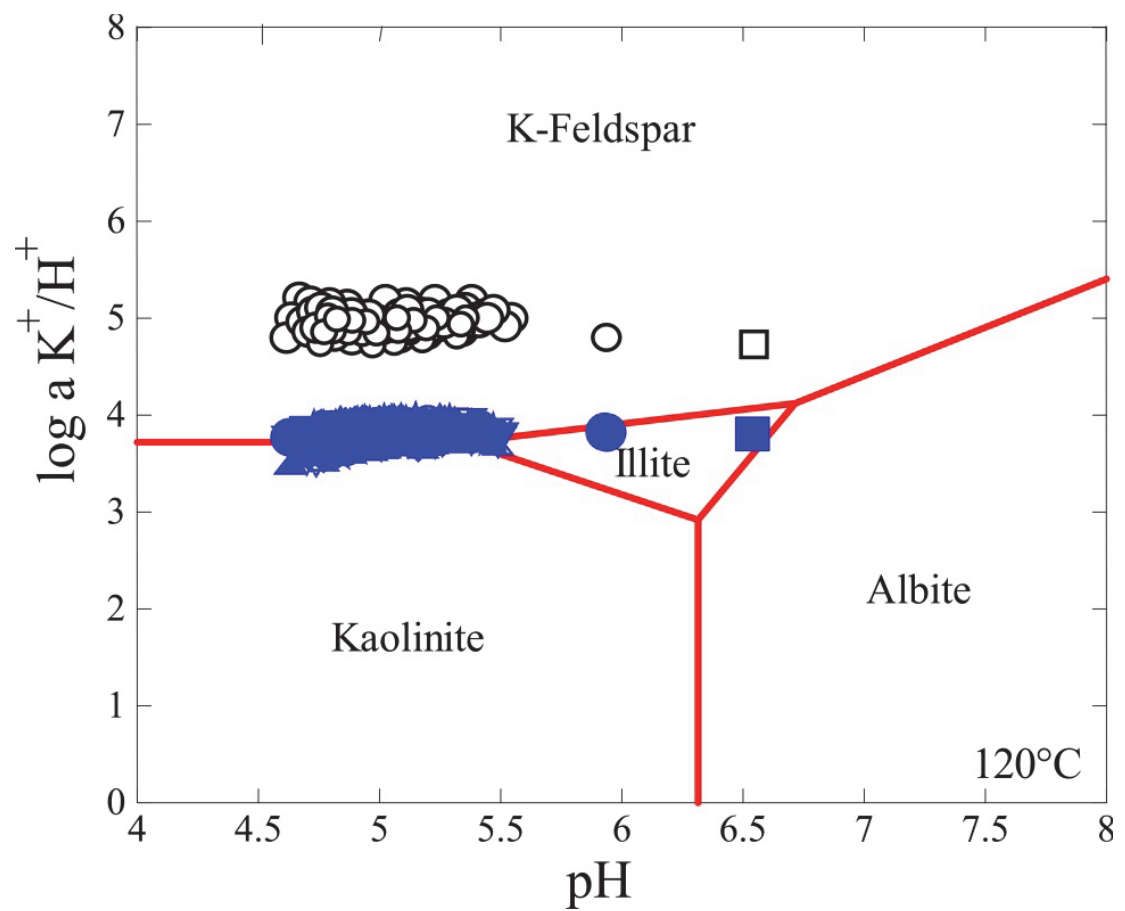

244 Figure 7. Phase diagram for $\mathrm{K}_{2} \mathrm{O}-\mathrm{NaO}-\mathrm{SiO}_{2}-\mathrm{MgO}-\mathrm{Al}_{2} \mathrm{O}_{3}-\mathrm{H}_{2} \mathrm{O}$ system at $120^{\circ} \mathrm{C}$ with the 369 245 Bakken water samples plotted using wellhead and corrected $\mathrm{pH}$ (open and solid symbols, 246 respectively). Diagram made using GWB ACT2 module (Bethke, 1996).

As produced fluids are brought to the surface, degassing and shifts in temperature result in disequilibrium (e.g. Ahmadi et al. 2015). In the Bakken produced water samples, the measured $\mathrm{pH}$ values range between 5.6 and 8.2, but those measurements were made at the surface at lower temperatures $\left(4-35^{\circ} \mathrm{C}\right)$ and pressures $(1 \mathrm{bar})$ than prevail in the formation. We calculated the saturation index for calcite using the reported calcium, alkalinity and both the wellhead $\mathrm{pH}$ data, and the calculated in situ $\mathrm{pH}$.

254 The calcite saturation indices calculated with the wellhead and in situ $\mathrm{pH}$ values are shown in 255 Figure 8. The saturation indices for the in situ $\mathrm{pH}$-calculated values plot at or slightly under256 saturated with respect to calcite. Saturation indices calculated using wellhead $\mathrm{pHs}$ are calculated 257 to be over-saturated The near-saturation with respect to calcite in situ is reasonable because of 258 the presence of calcite in the formation and its relatively high reactivity.

259 To further evaluate the calculated reservoir $\mathrm{pH}$, we compared the $\mathrm{pCO}_{2}$ values calculated using 260 the wellhead $\mathrm{pH}$ versus the calculated $\mathrm{pH}$ to Bakken gas analyses. Figure 9 shows calculated $261 \mathrm{pCO}_{2}$ versus TDS for wellhead and in situ values. Based on $\mathrm{CO}_{2}$ gas analyses averaging 0.57 262 mole\% (Wocken et al. 2013) and an average depth of 10,227, a $\mathrm{pCO}_{2}$ value of about $1.5 \mathrm{bar}(\log$ $263 \mathrm{pCO}_{2}$ of 0.1 ) was calculated. The $\mathrm{pCO} 2$ values using the calculated in situ $\mathrm{pH}$ show good 
264 agreement with the measured $\mathrm{CO}_{2}$ content of produced gas further supporting the calculation of 265 the in situ $\mathrm{pH}$ values.

266 We note that since most of the reported analyses do not have $\mathrm{pCO}_{2}$ values near atmospheric (log $267 \mathrm{pCO}_{2}=-3.5$ ) indicating that the samples had not fully equilibrated with surface conditions.

268 Therefore, Bakken produced water can precipitate more calcite if given sufficient time to reach 269 equilibrium. This process will occur in the separators and surface installations.

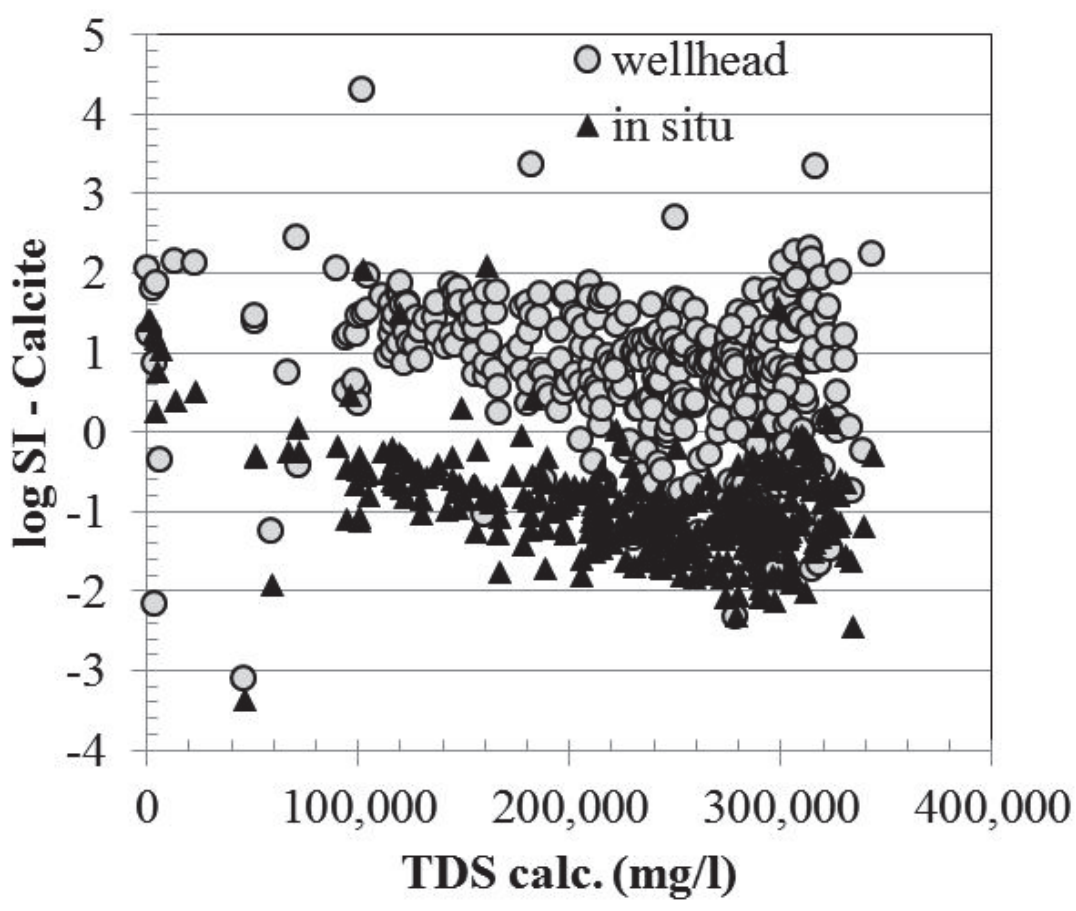

271 Figure 8. Calculated calcite saturation index for 310 Bakken produced water analyses with 272 wellhead and in situ pH (PHREEQC with llnl database). 


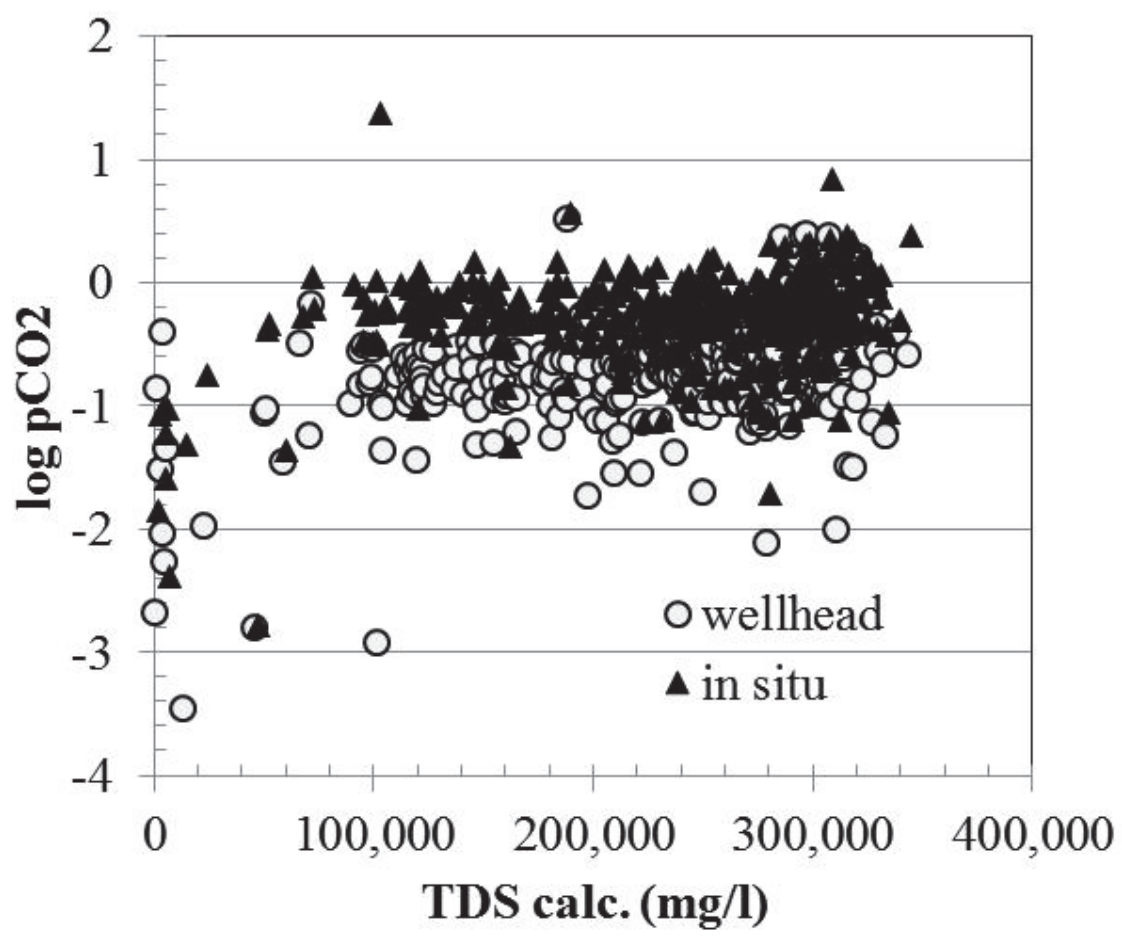

274

275 Figure 9. Plot of calculated $\mathrm{pCO}_{2}$ versus TDS for Bakken water samples assuming equilibrium with calcite and wellhead and reservoir pH (PHREEQC with llnl database).

277 In summary, the general approach of correcting $\mathrm{pH}$ values to reservoir conditions produces reasonable results. Some of the simplifications, such as using an average temperature for samples lacking data, introduce uncertainty, but the overall trends are consistent with the 280 expected results.

\section{Discussion}

282 Water analyses impacted by scale formation will have calcium and alkalinity values lower than reservoir values. We can restore the water analyses to in situ values by adding calcite to the reported solutions to reach equilibrium with calcite and anhydrite at reservoir $\mathrm{pH}$ (Hitchon, 1996). Using this approach we restore several water analyses and then simulate production changes. A model for Bakken brine (SN 17150000) assumed equilibrium with calcite and anhydrite as the starting condition. Scale precipitation is simulated for 10 Bakken brines by using the in situ chemistry as the starting point and then lowering temperature to $25^{\circ} \mathrm{C}$ and $\mathrm{CO}_{2}$ fugacity to atmospheric using the geochemical model (see Table 1).

290 Bakken wells produce significant amounts of scale, mostly calcite with minor anhydrite and 291 halite (Cenergy et al. 2011, Wylde et al. 2012). The severity of scaling is related to time of 
production with relatively early (Cenergy et al. 2011) and later periods (Wylde et al. 2012) being the most difficult. The average water volume used in the Bakken is about 900,000 gallons/well (LaFollette et al. 2012). For a Bakken well that produces water at about 1500 barrels/month for 48 months (about $3 \mathrm{M}$ gallons of fluid), this equates to approximately 2 million gallons of formation water during well life assuming complete recovery of fracking fluid.

The calculations show that calcite scale forms in response to the $\mathrm{pH}$ change triggered by the decrease in pressure, and could be as much as 0.045 grams per liter, while the precipitation of halite and anhydrite did not occur except from the most saline samples. This means early flowback will produce little or no halite or anhydrite, but later produced water may generate these other scales as TDS approaches the highly saline formation water levels, consistent with observations (Wylde et al. 2012).

Table 1 shows an example of calculated scale volume for the selected ten brines. The geochemical models predict calcite scale forms early in the production process, consistent with the observations of scale in production tubing and surface equipment (Cenergy et al, 2011). Calcite may also form in the fractures and near well-bore area depending on the amount of pressure reduction. There are also scale formation scenarios that this analysis does not consider. For example, the local cooling and pressure drops that can occur in fractures or near perforations when gas flashes from oil can produce calcite scale. The pressure drop can also produce a separate gas phase that will cause water to partition into the gas out of the aqueous phase increasing the salinity locally. Under those conditions the salinity may increase enough to precipitate anhydrite and halite from the saline produced water.

Table 1. Amount of calculated scale for Bakken produced water sample.

\begin{tabular}{|c|c|c|c|c|c|}
\hline & & Scale & & & \\
\hline PW (lbs/mo) & PW (bbls/mo) & $\begin{array}{c}\text { calcite } \\
\text { (kg/month) }\end{array}$ & $\begin{array}{c}\text { 4 years } \\
(\mathrm{kg})\end{array}$ & $\mathrm{cm}^{3} / \mathrm{month}$ & $\mathrm{in}^{3} /$ month \\
\hline 3,507 & 10 & 0.07 & 3 & 26 & 2 \\
\hline 17,535 & 50 & 0.36 & 17 & 132 & 8 \\
\hline 87,675 & 250 & 1.79 & 86 & 659 & 40 \\
\hline 175,350 & 500 & 3.57 & 171 & 1,318 & 80 \\
\hline 263,025 & 750 & 5.36 & 257 & 1,977 & 121 \\
\hline 350,700 & 1000 & 7.14 & 343 & 2,636 & 161 \\
\hline 438,375 & 1250 & 8.93 & 429 & 3,295 & 201 \\
\hline 526,050 & 1500 & 10.72 & 514 & 3,954 & 241 \\
\hline 613,725 & 1750 & 12.50 & 600 & 4,613 & 282 \\
\hline 701,400 & 2000 & 14.29 & 686 & 5,272 & 322 \\
\hline
\end{tabular}

Note: $1500 \mathrm{bbls} / \mathrm{month}$ of Bakken brine for 48 months is 3.03 million gallons of water, scaling potential is based on sample SN 17150000. 
315 The long-residence time and high temperature of connate water in geological settings such as the 316 middle Bakken makes k-feldspar-clay equilibrium likely (Thyne et al., 2001). To test this

317 hypothesis we first assume that clay growth is faster than feldspar dissolution, which limits the 318 overall reaction. The lab-measured neutral $\mathrm{pH}$ dissolution rate of $\mathrm{k}$-feldspar dissolution is $\sim 10^{-}$

$319{ }^{12.4} \mathrm{~mol} / \mathrm{m}^{2} \mathrm{~s}$ at $25^{\circ} \mathrm{C}$; the activation energy is $9.1 \mathrm{kcal} / \mathrm{mol}$ (Palandri and Kharaka, 2004). The 320 calculated $120^{\circ} \mathrm{C} \mathrm{k}$-feldspar dissolution rate is therefore $\sim 10^{-10.8} \mathrm{~mol} / \mathrm{m}^{2} \mathrm{~s}$. Using a porosity of $3217 \%$, a k-feldspar content of 5\% (e.g. Alexandre et al., 2012), and assuming a k-feldspar surface 322 area of $0.1 \mathrm{M}^{2} / \mathrm{g}$, we calculate an in situ k-feldspar dissolution rate of $\sim 0.03 \mathrm{~mol} / \mathrm{Lyr}$. This 323 means that to provide the amount of potassium seen in middle Bakken connate water, $\sim 0.025 \mathrm{M}$, 324 roughly a year of k-feldspar dissolution would be required. This is almost certainly an 325 underestimate of the time required for equilibration because lab rates tend to be at least an order 326 of magnitude lower than field-based rates because of fewer reactive sites and affinity effects. 327 Nevertheless, feldspar-clay rates are still likely to be fast enough to reach equilibrium, and 328 control in situ $\mathrm{pH}$, over fluid residence times greater than thousands of years. But feldspar-clay 329 reactions may be too slow to control in situ $\mathrm{pH}$ during fracking and flowback which occur over 330 residence times of months.

331 Dissolution of feldspar to form clay minerals is kinetically slower than dissolution/precipitation 332 of calcite and anhydrite at near-surface temperatures. Although dolomite growth is kinetically 333 hindered at these temperatures (e.g. Brady et al., 1996), the presence of authigenic dolomite in 334 the middle Bakken suggests that under reservoir conditions dolomite formation is not kinetically 335 hindered. Our hypothesis is that k-feldspar, quartz, and dolomite do not equilibrate over the 336 much shorter time-scales, and lower temperatures, of fracking and flowback (a few months at 337 most). This means that $\mathrm{pH}$ control of in situ fluids and flowback pumped to the surface is driven 338 by much more rapid equilibration with calcite and anhydrite/gypsum. The geochemical models 339 using these assumptions produce realistic scale predictions.

\section{Conclusions}

342 A thermodynamic approach to restoring formation water was performed for $\mathrm{pH}$ by assuming that

343 in situ $\mathrm{pH}$ and portions of the water chemistry is controlled by mineral equilibrium. The 344 technique produces realistic results for the Bakken formation. Most produced water has not 345 reached equilibrium with surface conditions as indicated by elevated $\mathrm{pCO}_{2}$ values calculated 346 from the reported analyses.

347 The results show that calcite scale formation is highly dependent on pressure reduction rather 348 than temperature changes and will be produced in the both production tubing and surface 
facilities. Calcite scale potential appears to be less in the lower TDS flowback and is greater in higher TDS brine later in well life.

Anhydrite and halite scale is possible, but probably only when produced water salinity increases, such as during water partitioning into the gas phase raising salinity locally. Thus, anhydrite and halite scale formation is not predicted for most produced water samples. Only the very saline water is produced after flowback later in the well history is likely to be able to form these scales.

\section{Acknowledgments}

We greatly appreciate funding from the Sandia Laboratory Directed Research and Development office. Sandia is a multiprogram laboratory operated by Sandia Corporation, a Lockheed Martin Company, for the United States Department of Energy's National Nuclear Security Administration under contract DE-AC04-94AL85000.

\section{References}

Ahmadi, M-A., Bahadori, A. and S.R. Shadizadeh, 2015, A rigorous model to predict the amount of dissolved calcium carbonate concentration throughout oil field brines: Side effect of pressure and temperature. Fuel 139, 154-159.

Alexandre, C.S., Sonnenberg, S. and Sarg, J. 2012, Diagenesis of the Bakken Formation, Elm Coulee Field, Richland County, Montana, AAPG Annual Convention and Exhibition. the evolution of porosity. Applied Geochemistry 8, 285-298.

372 Bull. 80, 248-264.

373 Bader, M.D.H., 2006, Sulfate scale problems in oil fields water injection operations. Desalination 201, 374 100-105.

375 Baraka-Lokmane, S. and K. Sorbie, 2010, Effect of $\mathrm{pH}$ and scale inhibitor on phosphonate-carbonate 376 interaction. J. Petrol. Sci. Eng. 70, 10-27.

377 Bethke, C.M., 1996, Geochemical Reaction Modeling, Oxford University Press, 397p.

378 Boschee, P., 2014, Produced and flowback water recycling and reuse. Oil and Gas Facilities, February, 379 16-21. 
Brady, P.V., Krumhansl, J.L. and Papenguth, H.W. 1996, Surface complexation clues to dolomite growth. Geochim. Cosmochim. Acta 60, 727-731.

Cenergy, L.M., McAfee, C.A. and L.J. Kalfayan, 2011, Field study of the physical and chemical factors affecting downhole scale deposition in the North Dakota Bakken Formation. SPE 140977.

Capuano, R.M., 1990, Hydrochemical constraints on fluid-mineral equilibria during compaction diagenesis of kerogen-rich geopressured sediments. Geochimica et Cosmochimica Acta 54, 1283-1299. determine the composition of scale deposition. Desalination 249, 748-756.

Fan, C., Kan, A.T., Zhang, P., Lu, H., Work. S., Yu, J and M.B. Mason, 2010, Scale prediction and inhibition for unconverntional oil and gas production. SPE 130690.

Fu, Y. van Berk, W. and H-M. Schulz, 2012, Hydrogeochemical modeling of fluid-rock interactions triggered by seawater injection into oil reservoirs: case study Miller field (UK North Sea). Applied

392 Geochemistry 27, 1266-1277.

Fu, Y. van Berk, W. and H-M. Schulz, 2013, Temporal and spatial development of scale formation: Onedimensional hydrogeochemical transport modeling. J.Petrol. Sci. Eng. 112, 273-283.

Ghosh, B and X. Li, 2013, Effect of surfactant composition on reservoir wettability and scale inhibitor squeeze lifetime in oil wet carbonate reservoir. J. Petrol. Sci. Eng.108, 250-258.

397 Gomes, R.M., Mackay, E.J., Deucher, R.H., Bezerra, M.C.M., Roasrio, F.F. and M.M. Jordan, 2012, 398 Impact of reservoir reactions on thermodynamic scale predictions. SPE 155255.

Güler, C. and G.D. Thyne, 2004, Hydrologic and geologic factors controlling surface and groundwater chemistry in Indian Wells-Owens Valley area, southeastern California, USA. J. Hydorology 285, 177-198.

Gupta, D.V.S., Carman, P., and R. Venugopal, 2012, A stable fracturing fluid for produced water applications. SPE 159837.

406 Haghtalab, A., .J. Kamali and A. Shahrabadi, 2014, Prediction mineral scale formation in oil reservoirs during water injection. Fluid Phase Equilibria 373, 43-54. authigenic mineral assemblages: Are they in metastable equilibrium in hydrocarbon reservoirs? Geochimica Cosmochimica Acta 57, 3295-3339. 
414

Holubnyak, Y.I., Bremer, J.M., Mibeck, B.A.F., Hamling, J.A., Huffman, B.W., Klapperich, R.J., Smith, S.A., Sorensen, J.A. and J.A. Harju, 2011, Understanding the souring at Bakken oil reservoirs. SPE 141434.

Houston, S.J., Yardley, B. W.D., Smalley, P.C. and I. Collins, 2007, Rapid fluid-rock interaction in oilfield reservoirs. Geology 35, 1143-1146.

Hutcheon, I., Shevalier, M., and H.J. Abercrombie, 1993, pH buffering by metastable mineral-fluid equilibria and evolution of carbon dioxide fugacity during burial diagenesis. Geochimica Cosmochimica Acta 57, 1017-1027.

Iampen, H.T. and B.J. Rostron, 2000, Hydrogeochemistry of the pre-Mississippian brines, Williston Basin, Canada-USA. J. Geochemical Explor. 69-70, 29-35.

Kan, A.T.and M.B. Tomson, 2012, Scale prediction for oil and gas production. SPE Journal, June, 362378.

Kan, A. T., Zhang, N., Shi, W., Wang, K., Wang, L., Yan, F. Tomson, M.B., Tomson, M.B., Zhu, H., and S.M.A. Razavi, 2013, Interrelationship of $\mathrm{CO}_{2}$, weak acids, bases and $\mathrm{pH}$ in scale prediction and control. SPE 164127.

Kodel, K.A., Andrade, P.F., Valenca, J.V.B., and D. N. Souza, 2012, Study on the composition of mineral scales in oil wells. J. Petrol. Sci. Eng. 81, 1-6.

Kurtoglu, V, Kazemi, H, Rosen, R., Mickelson, W, and T. Kosanke, 2014, A rock and fluid study of the middle Bakken Formation: Key to enhanced oil recovery. SPE 171688-MS.

Lundergrad, P. D. and L. S. Land, 1989, Carbonate equilibria and $\mathrm{pH}$ buffering by organic acids-response to change in pCO2. Chemical Geology 74, 277-287.

Mahmoud, M.A., 2014, Evaluating the damage caused by calcium sulfate scale precipitation during low- and high-salinity-water injection. Journal of Canadian Petroleum Technology, May, 141150.

Miller, D.G., Pinwinskii, A.J. and R Yamauchi, 1976, Geochemical equilibrium codes: A means of modelling precipitation phenomena in the Salton Sea geothermal field. SPE 6604.

Moghadasi, J., Muller-Steinhagen, H., Jamialahmadi, M., and A. Sharif, 2004, Model study on the kinetics of oil field formation damage due to salt precipitation from injection. J. Petrol. Sci. Eng. 43, 201207.

Palandri, J.L. and Kharaka, Y.K., 2004, A compilation of rate parameters of water-mineral interaction kinetics for application to geochemical modeling. USGS Open File Report 2004-1068.

Parkhurst, D.L. and C.A.J. Appelo, 1999, User's guide to PHREEQC (Version 2) - A computer program for the speciation, batch-reaction, one dimensional transport and inverse modeling geochemical calculations. USGS WRI Report 99-4259. 326p. 
Pitman, J.K., Price, L.C. and J.A. LeFever, 2001, Diagenesis and fracture development in the Bakken Formation, Williston Basin: Implications for reservoir quality in the Middle Member. USGS

450 Professional Paper 1653, 24p.

451 Ramakrishna, S. Balliet, R., Miler, D., Sarvotham, S. and D. Merkel, 2010, Formation evaluation in the 452 Bakken complex using laboratory data and advanced logging technologies. SPWLA 51 ${ }^{\text {st }}$, Logging Sypm.

453 Smalley, P.C. and E. A. Warren, 1994, North Sea formation water: implications for diagenesis and 454 production chemistry. Marine and Petroleum Geology 11, 1-2.

455 Smith, J.T. and S. N. Ehrenberg, 1989, Correlation of carbon dioxide abundance with temperature in 456 clastic hydrocarbon reservoirs: relationship to inorganic chemical equilibrium. Marine and Petroleum 457 Geology 6, 129-135.

458 Thyne, G.D., Boudreau, B., Ramm, M. and Midtbø, R.E., 2001, A reaction-transport model of K-spar dissolution and illitization in the Statfjord Formation, North Sea. AAPG Bulletin 85, 621-636. SPE 145684.

USGS Produced Water Database, 2016,

466 USGS Produced Water Database, 2015, http://www.usgs.gov/science/cite-view.php?cite=1259

467 Wocken, C.A., Stevens, B.G., Almlie, J.C. and S.M. Schlasner, 2013, End-use Technology Study - An 468 assessment of alternative uses for associated gas. Energy and Environmental Research Center 136p.

469 Wylde, J.J., Salyer, J.L., and B. Frehlick, 2012, An exhaustive study of scaling in the Canadian Bakken:

470 Failure mechanisms and innovative mitigation strategies from over 400 wells. SPE 153005.

471 Zahedzadeh, M., Karambeigi, M.S., Roayaei, E., Emadi, M.A., Radnehr, M., Gholamianpur, H., Ashoori, 472 S., and S. Shokrollahzadeh, 2014, Comprehensive management of mineral scale deposition in carbonate 473 oil fields - A case study. Chemical Eng. Res. Des. 92, 2264-2272.

474 Zhang, Y., Samuelsen, E., Frederiksen, R., Roberts, D. and B. Ginty, 2010, Calcite scale prediction and 475 management in a chalk reservoir - field cases. SPE 130410.

476 Zhou, J., Cutler, J., Morsy, S., Morse, A., Sun, H., and Q. Qu, 2014a, Enhancing well stimulation with 477 improved salt tolerant surfactant for Bakken Formation. SPE 169141.

478 Zhou, J. Baltazar, M., Sun, H. and Q. Qu, 2014b, Water-based environmentally preferred friction reducer 479 in ultrahigh-TDS produced water for slickwater fracturing in shale reservoirs. SPE 169775. 